\title{
MRI-guided segmental sternectomy for impalpable intraosseous lesion
}

\author{
Francesco Petrella ${ }^{1,2}$, Monica Casiraghi ${ }^{1}$, Niccolò Filippi ${ }^{1}$, Riccardo Orlandi ${ }^{1}$, Andrea Alliata ${ }^{1}$, \\ Giorgio Lo Iacono ${ }^{1}$, Luigi Funicelli ${ }^{3}$, Stefania Rizzo ${ }^{4}$, Lorenzo Spaggiari ${ }^{1,2}$ \\ ${ }^{1}$ Department of Thoracic Surgery, IRCCS European Institute of Oncology, Milan, Italy; ${ }^{2}$ Department of Oncology and Hemato-oncology, \\ University of Milan, Milan, Italy; ${ }^{3}$ Department of Radiology, IRCCS European Institute of Oncology, Milan, Italy; ${ }^{4}$ Department of Radiology, EOC- \\ Institute of Imaging of the Italian Switzerland, Lugano, Switzerland \\ Correspondence to: Francesco Petrella, MD, PhD. Department of Thoracic Surgery, European Institute of Oncology - Via Ripamonti, 435, Milan, \\ Italy. Email: francesco.petrella@ieo.it; francesco.petrella@unimi.it.
}

Submitted Jul 15, 2019. Accepted for publication Jul 22, 2019.

doi: $10.21037 /$ jtd.2019.07.91

View this article at: http://dx.doi.org/10.21037/jtd.2019.07.91

\section{Introduction}

The sternum is an uncommon site for neoplastic lesion and so sternectomy for oncologic indications is rare $(1,2)$. Primary tumors of the sternum represent $0.5 \%$ of all primary bone neoplasms, being chondrosarcoma the most frequent, occurring mainly in young male patients (3). The sternum can be the site of isolated bone metastasis from non-bone primary tumors and sternectomy can be indicated in very selected case.

Usually resection of the sternum is limited to surgical treatment of infections complicating cardiac and thoracic operations: in this case infection treatment and chest wall stability are the main goal (4); on the contrary, when radical resection is required for oncologic reasons, wide margins need to be obtained and chest wall reconstruction may require prosthetic devices and its coverage by adequate muscle flaps (5).

Here we report a case of undiagnosed, increasing ${ }^{68}$ Gallium positron emission tomography (PET) positive lesion of the upper third of the sternal body in patient with a past history of a resected, well-differentiated, neuroendocrine tumor of the right colon in which computed tomography (CT) guided sternal biopsy was attempted but without any diagnoses.

Segmental sternectomy was planned for diagnostic and therapeutic approach.

\section{Surgical technique}

A 55-year-old male patient with a previous clinical history of a resected, well-differentiated, neuroendocrine tumor of the right colon was referred to our department because of an increasing ${ }^{68}$ Gallium PET positive lesion of the upper third of the sternal body (Figure 1). Magnetic resonance imaging (MRI) confirmed the focal lesion $11 \mathrm{~mm}$ in diameter within the body of the sternum (Figure 2), while CT scan did not disclose any findings.

A CT guided needle biopsy was attempted - on the basis of MRI and PET findings-but without any histologic results (Figure 3). After a multidisciplinary meeting, the need of a clear histology of the increasing sternal lesion was confirmed; the patient was then submitted to segmental sternectomy under MRI guidance.

Preoperative MRI allowed to identify the target lesion and to mark its projection on the skin.

Segmental sternectomy-involving the upper third of the sternal body and 2nd and 3rd sterno-chondral articulations on both sides was performed; chest wall reconstruction was performed by a polypropylene mesh/methylmethacrylate composite prosthesis that was then covered by a bilateral flap of pectoralis major muscles (Figure 4). Postoperative course was uneventful and the patient was discharged in good clinical conditions on postoperative day 6 .

\section{Discussion}

Unpalpable intraosseous lesions to be resected still represent a major challenge for thoracic surgeons: in fact, inappropriately placed skin incisions, incomplete tumor 

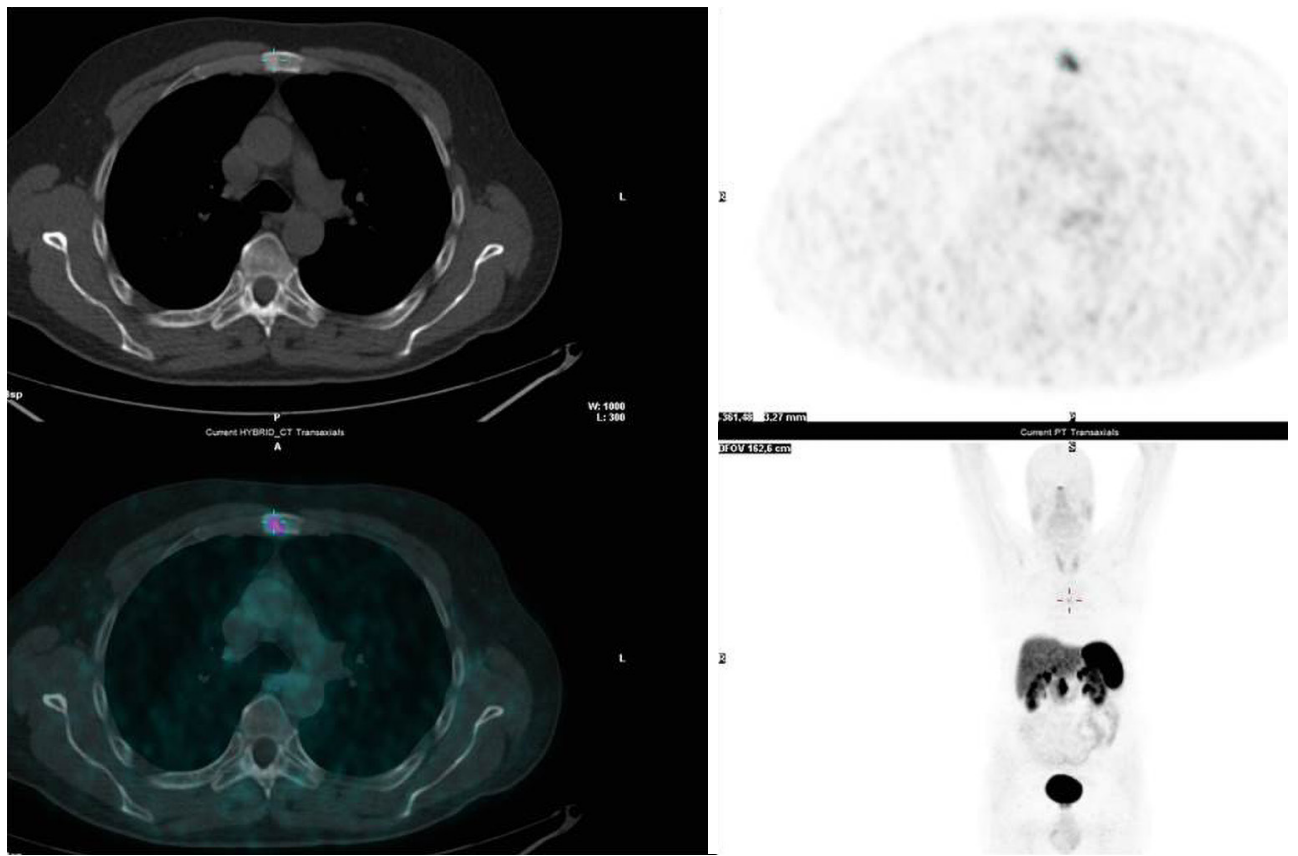

Figure 1 Preoperative ${ }^{68} \mathrm{Ga}$ PET scan.

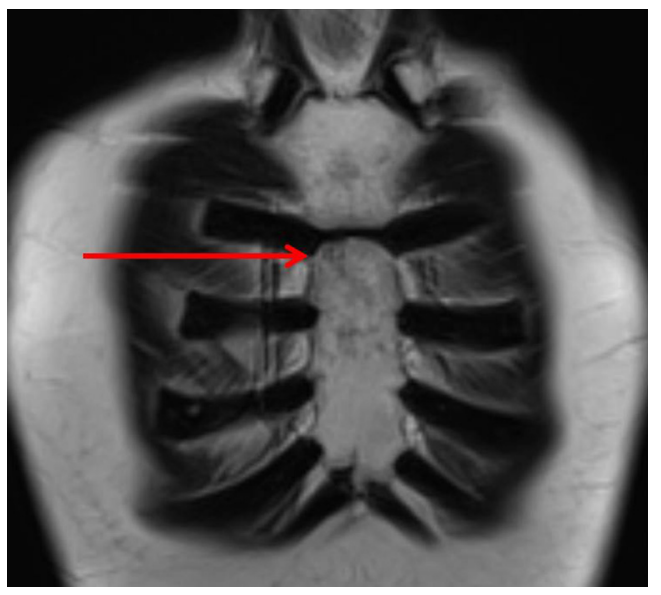

Figure 2 Preoperative magnetic resonance imaging disclosing intraosseous lesion of the upper third of the sternal body (red arrow).

excision or wrong segment resection may happen (7). Thanks to recent advancements, many focal bone lesions can be preoperatively detected by CT and PET scan (8) and marked by radioisotope injection.

On the contrary, complete intraosseous sternal lesion, not visible by CT scan, may represent a further challenge and MRI guide represents the ideal tool for an effective and

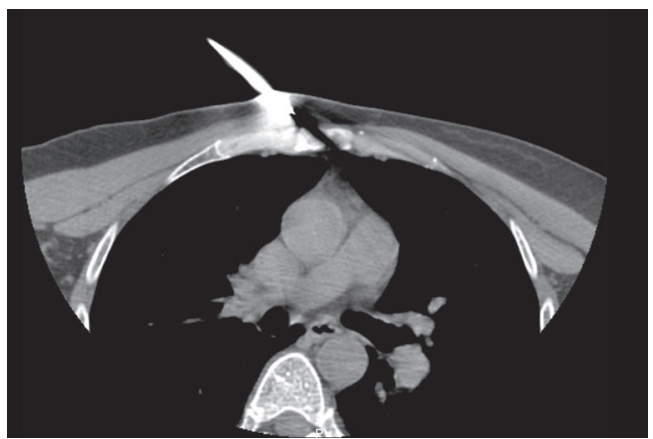

Figure 3 CT-guided biopsy attempt, without any histologic results.

precise preoperative mark.

Basic principles of segmental sternectomy are bilateral mammary vessels isolation and ligation above and below the interested segments as well as intercostal vessels ligation of the involved sterno-chondral articulations. Although many techniques and devices have been described for sternal reconstruction-ranging from basic prosthesis to sternal cadaveric allograft to 3D printing (9-12)—we still consider a polypropylene mesh/methylmethacrylate composite prosthesis one of the most suitable device. Adequate prosthesis coverage by wide muscular flaps is mandatory 


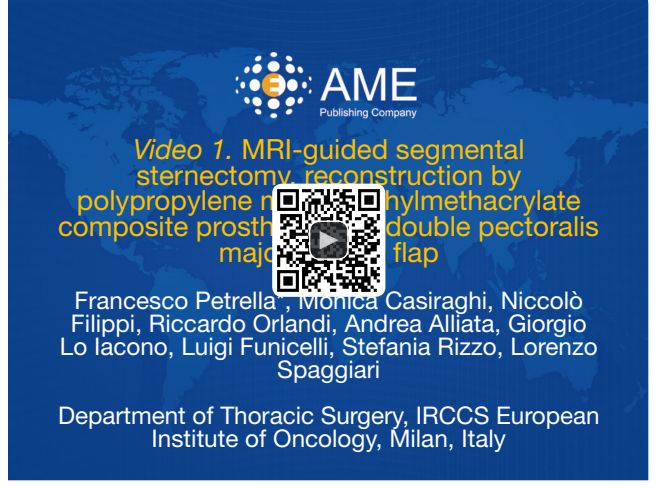

Figure 4 MRI-guided segmental sternectomy, reconstruction by polypropylene mesh/methylmethacrylate composite prosthesis and double pectoralis major muscle flap (6).

Available online: http://www.asvide.com/watch/33069

and bilateral pectoralis major muscle flaps can be considered the most appropriate if soft tissue resection is not required; on the contrary-if pectoralis muscles are involved by neoplastic tissue-latissimus dorsi muscle flap represents the best available option.

\section{Acknowledgments}

None.

\section{Footnote}

Conflicts of Interest: The authors have no conflicts of interest to declare.

Etbical Statement: The authors are accountable for all aspects of the work in ensuring that questions related to the accuracy or integrity of any part of the work are appropriately investigated and resolved. The patient was informed that his clinical data could be used for various clinical studies, and written informed consent was obtained on this basis.

\section{References}

1. Butterworth JA, Garvey PB, Baumann DP, et al. Optimizing reconstruction of oncologic sternectomy defects based on surgical outcomes. J Am Coll Surg 2013;217:306-16.

2. Pinheiro VEG, Bezerra BR, Farias LABG, et al. Sternectomy for Treating Advanced Non-Melanoma Skin
Cancer. J Skin Cancer 2019;2019:3948782.

3. Koppert LB, Van Geel AN, Lans TE, et al. Sternal resection for sarcoma, recurrent breast cancer, and radiation-induced necrosis. Ann Thorac Surg 2010;90:1102-8.

4. Petrella F, Arlati F, Mariolo, et al. Distal sternectomy for post-sternotomy chronic osteomyelitis. J Vis Surg 2018;4:195.

5. Petrella F, Radice D, Borri A, et al. Chest wall resection and reconstruction for locally recurrent breast cancer: From technical aspects to biological assessment. Surgeon 2016;14:26-32.

6. Petrella F, Casiraghi M, Filippi N, et al. MRI-guided segmental sternectomy, reconstruction by polypropylene mesh/methylmethacrylate composite prosthesis and double pectoralis major muscle flap. Asvide 2020;7:022. Available online: http://www.asvide.com/watch/33069

7. McDonald JM, Freeman RK. Thoracoscopic localization of nonpalpable rib tumors for excisional biopsy. Ann Thorac Surg 2000;70:318-9.

8. Choi HS, Yoo IeR, Park HL, et al. Role of ${ }^{18}$ F-FDG PET/ $\mathrm{CT}$ in differentiation of a benign lesion and metastasis on the ribs of cancer patients. Clin Imaging 2014;38:109-14.

9. Marulli G, Dell'amore A, Calabrese F, et al. Safety and Effectiveness of Cadaveric Allograft Sternochondral Replacement After Sternectomy: A New Tool for the Reconstruction of Anterior Chest Wall. Ann Thorac Surg 2017;103:898-905.

10. Dell'Amore A, Cassanelli N, Dolci G, et al. An alternative technique for anterior chest wall reconstruction: the sternal allograft transplantation. Interact Cardiovasc Thorac Surg 2012;15:944-7.

11. Meyer M, Neef H, Zerkowski HR. Alloplastic sternal replacement in malignant sternal tumors. Case report and review of the literature. J Cardiovasc Surg (Torino) 1998;39:853-7.

12. Wang L, Huang L, Li X, et al. Three-Dimensional Printing PEEK Implant: A Novel Choice for the Reconstruction of Chest Wall Defect. Ann Thorac Surg 2019;107:921-8.

Cite this article as: Petrella F, Casiraghi M, Filippi N, Orlandi R, Alliata A, Lo Iacono G, Funicelli L, Rizzo S, Spaggiari L. MRIguided segmental sternectomy for impalpable intraosseous lesion. J Thorac Dis 2020;12(1):42-44. doi: 10.21037/jtd.2019.07.91 